\title{
Pengembangan Media Pembelajaran Video Animasi Menggunakan Software Powtoon pada Materi SPLDV
}

\author{
Dika Garsinia $^{1}$, Ratih Kusumawati ${ }^{2}$, Arie Wahyuni ${ }^{3}$ \\ ${ }^{1}$ Universitas Ivet, dikagarsinia84@gmail.com \\ ${ }^{2}$ Universitas Ivet, kusumaratih91@gmail.com \\ ${ }^{3}$ Universitas Ivet, ariewahyuni20@gmail.com
}

\begin{abstract}
This research uses quantitative descriptive methods. The subjects of this study were 28 students of class VIII Al Bisyri Islamic Middle School. Data obtained by observation, questionnaire, and written test. ADDIE development model (Analysis, design, development, implementation, and evaluation). Data collection instruments used in the form of learning media questionnaires, student response questionnaires, rational test results. From the results of the research process obtained the value of media experts with an average score of 87.08 (good category), while the mathematics teacher material experts obtained an average score of 88.57 (very good category) so that the media included in the valid category. From the results of the practicality of Powtoon animation video learning media obtained an average score of 84.96 (practical categories), so that it meets the practical aspects in terms of effective, interactive, interesting, efficient, and creative. Whereas based on the posttest value which is higher than the pretest value, the posttest value is 81.50 higher than the pretest value of 67.57 that the effective learning media is used. Based on this analysis it can be concluded that the video animation media using Powtoon software has fulfilled valid, practical and effective criteria.
\end{abstract}

Keywords: Learning Media, Powtoon, EDDIE, SPLDV.

\begin{abstract}
ABSTRAK
Penelitian ini menggunakan metode deskriptif kuantitatif. Subjek penelitian ini adalah siswa kelas VIII SMP Islam Al Bisyri yang berjumlah 28 siswa. Data diperoleh dengan observasi, angket, dan tes tertulis. Model pengembangan $A D D I E$ (Analysis, design, development, implementation, dan evaluation). Instrumen pengumpulan data yang digunakan berupa angket media pembelajaran, angket respon siswa, test hasil bejalar. Dari hasil proses penelitian didapat nilai ahli media dengan skor rata-rata 87,08 (kategori baik), sedangkan oleh ahli materi guru matematika diperoleh skor rata-rata 88,57 (kategori sangat baik) sehingga media termasuk dalam kategori valid. Dari hasil angket kepraktisan media pembelajaran video animasi Powtoon diperoleh skor rata-rata 84,96 ( kategori praktis), sehingga memenuhi aspek kepraktisan yang ditinjau dari efektif, interaktif, menarik, efisien, dan kreatif. Sedangkan berdasarkan nilai posttest yang lebih tinggi dari pretest yaitu nilai posttest 81,50 lebih tinggi dari nilai pretest 67,57 bahwa media pembelajaran
\end{abstract}

Tanggal Masuk: 27 Februari 2020; Revisi: 19 April 2020; Diterima:29 April 2020 
efektif digunakan. Berdasarkan analisis tersebut dapat disimpulkan bahwa media video animasi menggunakan software powtoon telah memenuhi kriteria valid, praktis dan efektif.

Kata Kunci: Media Pembelajaran, Powtoon, EDDIE, SPLDV

\section{Pendahuluan}

Perkembangan teknologi informasi menuntut dunia pendidikan untuk selalu dan senantiasa menyesuaikan, terutama penggunaan bagi dunia pendidikan khususnya dalam proses pembelajaran. Muhson [1] mengemukakan dampak kemajuan teknologi mempengaruhi sarana pendidikan khususnya dalam penggunaana peralatan pembelajaran di sekolah.

Pesatnya perkembangan teknologi di dunia pendidikan menuntut keterampilan guru menggunakan teknologi dalam mengelola pembelajaran di kelas. Tugas seorang guru dalam proses belajar mengajar tidak hanya sebagai penyampai informasi kepada peserta didik. Tugas seorang guru bukan semata-mata tugas formal akan tetapi keterpanggilan kemanusian untuk membimbing, melayani, mengarahkan, menolong, memotivasi, dan memberdayakan sesama, khususnya pada peserta didiknya Hasyim [2].

Menurut Abdullah [3], Pembelajaran yang efektif dan efisien merupakan tuntutan guru dalam menyediakan bahan ajar atau materi awal. Keefektifan proses pembelajaran dimulai dari awal mempersiapkan sarana atau media pembelajaran sehingga isi pesan pengajaran tersampaikan Arsyad [4]. Menurut pendapat Daryanto [5], pembelajaran yang menampilkan gambar gerak merupakan bahan ajar yang akan sangat bermanfaat, sehingga mampu menarik perhatian dan motivasi siswa dalam melaksanakan kegiatan pembelajaran. Menurut Maryani [6], media pengajaran yang efektif adalah media pembelajaran interaktif berupa gambar, suara dan animasi. Sedangkan pendapat Sukiyasa \& Sukoco [7], media pembelajaran yang berupa gambar gerak visual dapat memotivasi siswa untuk mempelajarinya karena mudah diterima, dipahami dan lebih menarik.

Sangat jelas bahwa guru harus memanfaatkan media pembelajaran sebagai salah satu kebutuhan pokok dalam pembelajaran guna memotivasi siswa dalam menagkap dan memahami materi, sehingga siswa dapat fokus dengan media yang disampaikan guru.

Penelitian Raffaello Bryan Arnold [8], hasil penelitian ini mengembangkan media pembelajaran penjualan dengan menggunakan video animasi Powtoon yang sangat membantu interaksi siswa secara langsung saat pembelajaran.

Penelitian Ridha Yoni Astika, dkk [9], dari hasil penelitian dan pengembangan ini menghasilkan media pembelajaran berbantuan Powtoon pada materi Sistem Persamaan Linear Dua Variabel Kelas VII SMP dengan menggunakan model pengembangan 4-D menghasilkan produk media pembelajaran yang menarik.

Penelitian Desma Yulia [10], hasil penelitian menunjukkan bahwa dengan mengunakan pembelajaran Powtoon dapat mempengaruhi motivasi belajar siswa di Mat pelajaran Sejarah indonesia.

Penelitian Izomi Awalia, dkk [11], hasil penelitian di dapat bahwa media pembelajaran animasi Powtoon pada mata pelajaran matematika materi keliling dan luas bagun datar dikelas IV layak digunakan dan telah dikemas secara praktis sehingga memberikan manfaat bagi peserta didik.

Powtoon merupakan salah satu media pembuat pembelajaran yang memiliki fitur animasi yang menarik, dimana penggunaanya sama persis seperti power point. Yang membedakannya adalah pada Powtoon terdapat animasi tulisan tangan yang berbagai 
macam bentuk, animasi gambar kartun yang disesuaikan dengan karakter pembuat, dan efek transisi setiap layar dapat diganti sesuai keinginan, serta time line dapat diatur dengan mudah. Dengan fitur animasi yang menarik mempermudah guru dalam mengimplementasikan bahan ajar kedalam pembelajaran dikelas.

Dalam pembuatan materi menggunakan Powtoon dapat ditambahkan efek suara dimana suara yang digunakan bisa disesuaikan dengan karakter yang ditampilkan. Dari slide proses pembuatan sampai dengan hasil akhirnya dikemas dalam bentuk video. Alternatif dalam media pembelajaran adalah dalam bentuk video Awalia, Pamungkas, \& Alamsyah [11].

Pembelajaran dimana guru menyampaikan materi selama pelajaran berlangsung itu perlu dihindari karena tidak efektif dan membuat siswa didik merasa bosan. Kebiasaan guru yang hanya menjelaskan dengan contoh manual dipapan tulis menjadi salah satu faktor utama serta proses pembelajaran menggunakan pembelajaran konvensional, media visual yang digunakan berbentuk kertas dan media berupa alat peraga. Salah satu materi yang digunakan adalah SPLDV dimana penerapan materi tersebut apabila menggunakan Powtoon akan lebih mudah siswa untuk memahaminya. Maka dalam penelitian ini, peneliti akan mengembangkan media pembelajaran dengan menggunakan video animasi software Powtoon. Melalui media pembelajaran video animasi dapat membantu siswa dalam memahami materi dan membantu guru dalam memberikan soal-soal latihan yang menarik.

\section{Metode Penelitian}

Dalam metode penelitian ini menggunakan model pengembangan ADDIE yaitu Analysis, design, development, implementation, dan evaluation. Waktu pelaksanaan Penelitian ini dilaksanakan di bulan November 2019 di SMP Islam Al Bisyri Semarang. Penelitian pengembangan adalah cara yang efektif dalam membuat produk yang dapat diujikan Sugiyono [12]. Produk yang dijujikan adalah media pembelajaran video animasi Powtoon pada materi SPLDV.

Instrumen pengumpulan data diambil berupa angket media pembelajaran, angket respon siswa, test hasil bejalar. Keberhasilan siswa dalam pembelajaran adalah siswa telah mencapai nilai maksimal dari test yang diberikan. Arikunto [13] mengatakan soalsoal dalam sebuah test dapat mengukur kemampuan individu atau kelompok.nilai pengetahuan dan keterampilan.

Untuk teknik analisis data didapat dari ahli media dan ahli materi. validasi produk oleh ahli media dan materi menentukan kavalidan media yang dibuat. Skala likert yang digumakn peneliti terbagi lima kategori skor.

Tabel 1. Kriteria Validitas Produk

\begin{tabular}{cc}
\hline Interval & Kriteria \\
\hline $85 \% \leq$ skor $\leq 100 \%$ & Sangat Baik \\
$69 \% \leq$ skor $\leq 84 \%$ & Baik \\
$53 \% \leq$ skor $\leq 68$ & Cukup \\
$37 \% \leq$ skor $\leq 52 \%$ & Kurang Baik \\
$20 \% \leq$ skor $\leq 36 \%$ & Tidak Baik \\
\hline
\end{tabular}

Angket respon siswa untuk mengetahui kepraktisan dari produk. Sebaran angket diberikan kepada siswa setelah produk disampaikan. Implementasi penggunaan media 
pembelajaran video animasi dengan menggunakan Powtoon dilakukan uji ketuntasan dan uji banding pretest dan posttest

\section{Hasil dan Pembahasan}

Media pembelajaran video animasi menggunakan software Powtoon dikembangkan menggunakan model pengembangan dari ADDIE.

\subsection{Analysis}

Analisis kebutuhan berupa observasi awal dilakukan sebagai acuan pengembangan produk penelitian. Hasil yang didapat peneliti bahwa proses belajar mengajar di kelas guru masih kurang dalam menggunakan sarana dan prasana yang sudah difasilitasi dari sekolah. Kebosanan siswa dan ketidakfokusan siswa dapat dilihat saat seorang guru banyak memberikan materi yang disampaikan dengan menulis dipapan tulis serta dalam memberikan contoh soal dan latihan soal siswa didik sulit dalam menguraikan soal.

Alat-alat peraga pendukung matematika yang digunakan masih terbilang sangat minim. Kemampuan softskill guru di SMP Islam Al Bisyri dalam mengoperasikan kumputer dan perangkat lunak komputer terbilang cukup baik. Dengan tersedianya saran pendukung seperti LCD, speaker, proyektor, dan internet yang sediakan sekolah maka diperlukan pengembaangkan pembelajaran yang lebih baik dan tepat sehingga materi yang disampaikan mudah dipahami dan dipraktikkan. Media video animasi sebagai media pembelajaran akan sangat membantu dalam proses pembelajaran agar materi yang dikemas didalam video pembelajaran yang disampaiakan menjadi daya tarik siswa untuk bisa lebih focus serta siswa lebih mudah memahami materi yang disampaikan.

\subsection{Desain Produk}

Proses Pra Produksi dimana perencanaan awal dalam membuat video animasi pembelajaran dengan mempersiapkan bahan yang akan digunakan dalam proses produksi. Dalam tahap ini draf materi disiapkan terlebih dahulu, dan membuat storyboard agar memudahkan dalam proses produksi. Storyboard digunakan agar dalam menampilkan bahan-bahan yang akan di susun divideo media pembelajaran lebih mudah. Persiapan awal yang harus tersedia adalah kumputer yang sudah terkoneksi dengan internet dan software pendukung lainya seperti Wondershare Filmora Video Editor, Audacity, Format Factory sebagai pendukung mengelola dan mengedit gambar dan suara.

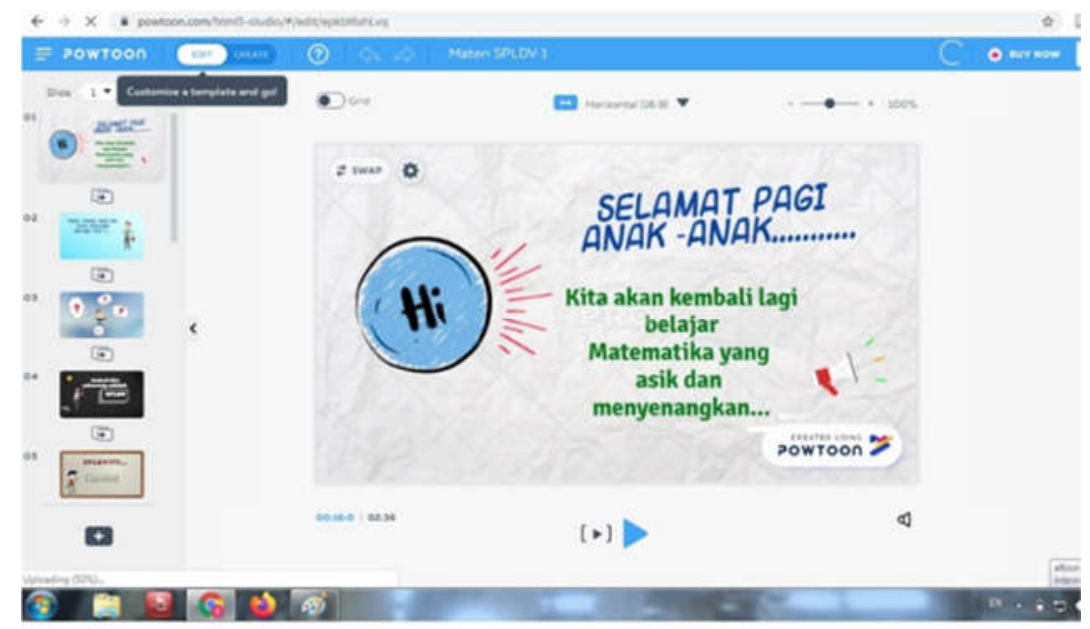

Gambar 1. Tampilan Pertama Pada Powtoon 
Proses produksi dilakukan menyesuaiakan dengan storyboard yang sudah dibaut. Setiap slide disusun rapih dengan menyajikan gambar dengan efek suara serta pengaturan time line yang selaras. Karakter animasi kartun yang diambil disesuaikan dengan karakter tokoh pada materi yang akan disampaikan. Properti dan setting background disesuiakan dengan ide cerita untuk menunjang tercapainya cerita. Pengisian suara untuk tiap karakter mengikuti naskah.

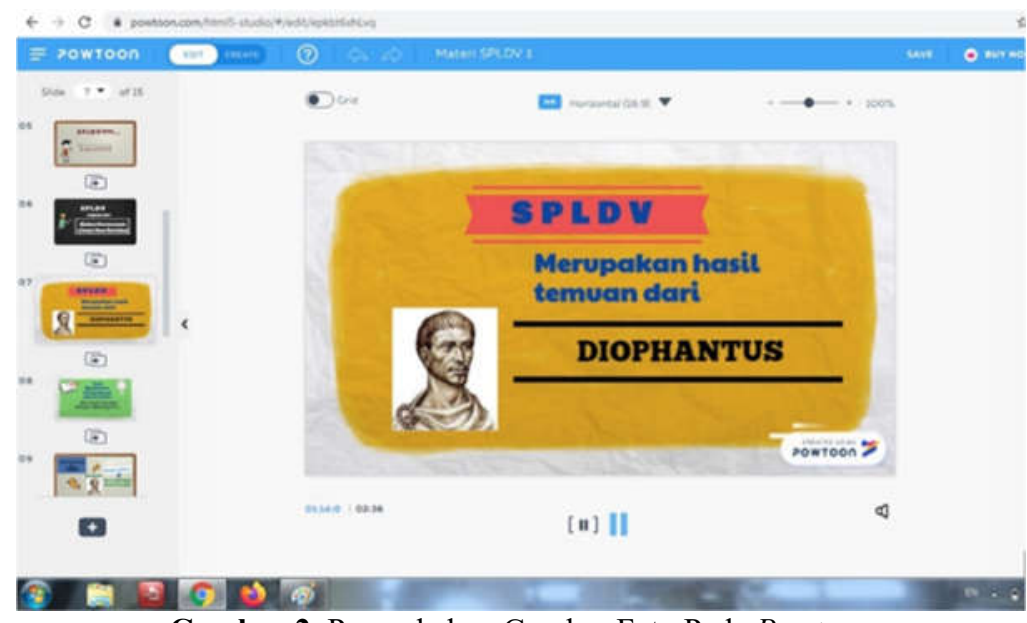

Gambar 2. Penambahan Gambar Foto Pada Powtoon

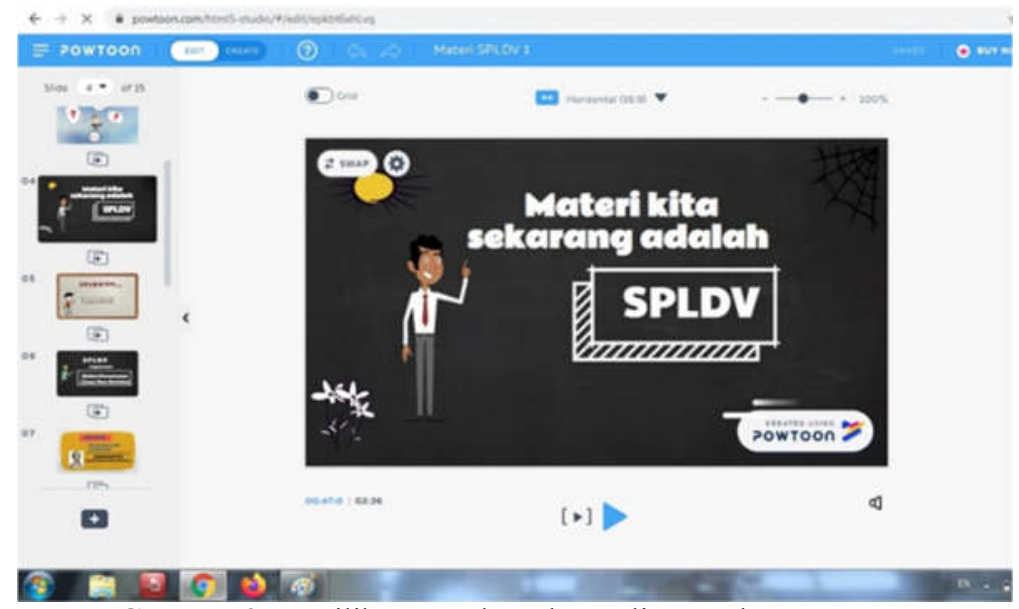

Gambar 3. Pemilihan Karakter dan Tulisan Dalam Powtoon

\subsection{Development}

Pada tahap ini produk yang sudah dibuat divalidasi terlebih dahulu sebelum di ujikan atau digunakan. Penelitian ini validasi oleh dua orang yanitu dosen Ivet sebagai validator ahli media dan guru matematika sebagai validator ahli materi. Validasi media dan materi oleh validator dengan menggunakan angket.

Untuk penilaian validasi ahli materi oleh guru matematika yaitu Ibu Siti Solekhah, S.Pd. Ahli materi memberikan penilaian yang terlihat pada Tabel 2.

Tabel 2. Validasi Ahli Materi

\begin{tabular}{ccc}
\hline Aspek Penilaian & Persentase ( \% ) & Kategori \\
\hline Pendidikan & 88,57 & Sangat Baik \\
Ketepatan & 88,57 & Sangat Baik \\
\hline
\end{tabular}


Pada tabel 2. Aspek penilaian pendidikan diperoleh dari rata-rata nilai total angket yang di peroleh dari pengisian ahli materi yang meliputi isi materi yang disajikan sesuia dengan materi yang disajikan dalam video animasi, video animasi pembelajaran tersusun secara sistematis, materi dalam video animasi pembelajaran mudah dipahamidan jelas. Pada aspek penilaian ketepatan diperoleh dari penyajian gambar, audio, dalam media video animasi pembelajaran sudah sesuai dengan materi. Untuk penilaian dari validasi ahli media pada media ini ialah dosen Matematika IVET. Ahli media memberikan penilaian yang terlihat pada Tabel 3 .

Tabel 3. Validasi Ahli Media

\begin{tabular}{ccc}
\hline Aspek Penilaian & Persentase ( \% ) & Kategori \\
\hline Media & 88,57 & Sangat Baik \\
Tampilan Program & 86,00 & Sangat Baik \\
Kualitas Teknis, & 86,67 & Sangat Baik \\
Keefektifan Program & & \\
\hline
\end{tabular}

\subsection{Implementation}

Pada tahap implementasi ini media pembelajaran video animasi menggunakan Powtoon diuji cobakan di kelas. Kelas yang diujicobakan satu kelas yaitu kelas VIII SMP Islam Al Bisyri. Pada tahap ini sebelum media di uji cobakan terlebih dahulu dilakukan pretest sebagai penilaian awal sebelum media itu digunakan. Pertemuan pertama pretest disini sebagai nilai yang didapat dari materi yang disampaikan tanpa menggunakan media.

Pada pertemuan kedua dan ketiga media diujicobakan dengan guru membuka pembelajaran terlebih dahulu dan siswa diberitahu untuk bisa menyimak materi video yang akan diberikan dengan menggunakan video animasi. Dalam proses pembelajaran siswa lebih fokus pada materi yang disajikan dengammenggunakan video animasi tampilan gambar kartun bergerak, suara serta slide yang membuat ketertarikan siswa semankin tinggi untuk memahami materi pelajaran, sehingga guru bisa memonitoring siswa saat pembelajaran berlangsung.

Pada pertemuan keemapat dilakukan posttest. Posttest digunakan sebagai penilaian siswa terhadap materi yang diberikan setelah menggunakan media pembelajaran video animasi Powtoon. Pada tahap ini juga siswa diberikan sebaran angket kepraktisan untuk menilai media yang digunakan tergolong dalam kelompok praktis atau tidak.

Rekapitulasi hasil lembar kepraktisan, uji kepraktisan ini dilakukan seperti pada Tabel.4

Tabel 4. Rekapitulasi Uji Kepraktisan

\begin{tabular}{ccc}
\hline Aspek & Persentase & Kategori \\
\hline Efektif & $83,2 \%$ & Praktis \\
Interaktif & $84,0 \%$ & Praktis \\
Menarik & $86,2 \%$ & Sangat Praktis \\
Efisien & $86,6 \%$ & sangat praktis \\
Kreatif & $84,8 \%$ & praktis \\
\hline
\end{tabular}

\subsection{Evaluasi}

Tahap evaluasi merupakan tahap terakhir untuk mengetahui apakah produk yang dihasilkan dapat mempengaruhi minat serta hasil belajar atau tidak. Dari hasil nilai pretest tanpa menggunakan media video animiasi Powtoon dan posttest yang dilakukan siswa 
yang mengerjakan soal SPLDV dengan yang menggunakan media video animasi apakah mempengaruhi hasil belajar.

Hasil pretest dan posttest dapat dilihat pada tabel 5.

Tabel 5. Uji Normalitas

\begin{tabular}{lcccccc}
\hline \multicolumn{8}{c}{ Tests of Normality } \\
\hline & Kolmogorov-Smirnov ${ }^{\mathrm{a}}$ & \multicolumn{3}{c}{ Shapiro-Wilk } \\
Hasil Post Test & Statistic & df & Sig. & Statistic & df & Sig. \\
\hline
\end{tabular}

Tabel 5. Menunjukan nilai Kolmogorov-Smirov Sig. Sebesar 0,200 >0,05 sehingga dapat disimpulkan bahwa hasil posttest berdistribusi normal.

Tabel 6. Uji Ketuntasan Nilai Rata-Rata Posttest

\begin{tabular}{|c|c|c|c|c|c|c|}
\hline \multicolumn{7}{|c|}{ One-Sample Test } \\
\hline & \multicolumn{6}{|c|}{ Test Value $=70$} \\
\hline & & & \multirow{2}{*}{$\begin{array}{l}\text { Sig. (2- } \\
\text { tailed) }\end{array}$} & \multirow{2}{*}{$\begin{array}{c}\text { Mean } \\
\text { Difference }\end{array}$} & \multicolumn{2}{|c|}{$\begin{array}{l}95 \% \text { Confidence Interval } \\
\text { of the Difference }\end{array}$} \\
\hline & $\mathrm{t}$ & df & & & Lower & Upper \\
\hline $\begin{array}{c}\text { Hasil } \\
\text { Post Test }\end{array}$ &, 300 & 27 & ,766 & ,393 & $-2,29$ & 3,08 \\
\hline
\end{tabular}

Tabel 6. Menunjukan nilai Sig.(2-tailed) adalah sebesar 0,766>0,05, maka sesuai kriteria Ho diterima dan Ha ditolak. Dengan demikian dapat diartikan bahwa nilai rata-rata hasil posttest sama dengan nilai KKM.

Tabel 7. Uji Normalitas Tes Awal (pretest) Dan Tes Akhir (posttest)

\begin{tabular}{ccccccc}
\hline \multicolumn{9}{c}{ Tests of Normality } & \multicolumn{3}{c}{ Shapiro-Wilk } \\
\hline & Kolmogorov-Smirnov & & \\
& Statistic & Df & Sig. & Statistic & df & Sig. \\
Hasil Post Test &, 131 & 28 &, $200^{*}$ &, 943 & 28 &, 131 \\
Hasil PreTest &, 101 & 28 &, $200^{*}$ &, 969 & 28 &, 559 \\
\hline
\end{tabular}

Tabel 7. Karena sample yang digunakan sebanyak 28 ( kurang dari 30) maka uji normalitas yang dipakai adalah Shapiro-Wilk. Tebel diatas tampak bahwa nilai signifikan dari posttest dan nilai prestest sebesar 0,131 dan 0,559 yang kurang dari 0,05 . Oleh karena itu dapat disimpulkan bahwa data diatas berdistribusi normal.

Tabel 8. Paired Sampel test (bandingan)

\begin{tabular}{|c|c|c|c|c|c|c|c|c|c|}
\hline \multicolumn{10}{|c|}{ Paired Samples Test } \\
\hline & & \multicolumn{5}{|c|}{ Paired Differences } & $\mathrm{t}$ & $\mathrm{df}$ & Sig. (2-tailed) \\
\hline & & \multirow[b]{3}{*}{ Mean } & \multirow{3}{*}{$\begin{array}{c}\text { Std. } \\
\text { Deviation }\end{array}$} & & \multirow{2}{*}{\multicolumn{2}{|c|}{$\begin{array}{l}95 \% \text { Confidence } \\
\text { Interval of the } \\
\text { Difference }\end{array}$}} & & & \\
\hline & & & & $\begin{array}{l}\text { Std. } \\
\text { Error }\end{array}$ & & & & & \\
\hline & & & & Mean & Lower & Upper & & & \\
\hline Pair 1 & $\begin{array}{l}\text { PreTest } \\
\text { Post Test }\end{array}$ & $-23,107$ & 14,292 & 2,701 & $-28,649$ & $-17,565$ & $-8,556$ & 27 &, 000 \\
\hline
\end{tabular}


Tabel 8. Pada tabel diatas menunjukan bahwa nilai sig. (2-tailed) adalah 0,000 yang artinya nilai signifikasi kurang dari 0,05 dengan rata-rata nilai pretest adalah 67,57 dan nilai rata-rata posttest adalah 81,50 , maka nilai rata-rata posttest lebih tinggi dari nilai rata-rata prestest. Dengan demikian dapat disimpilakn bahwa media pembelajaran yang digunakan sudah efektif digunakan untuk siswa.

\section{Kesimpulan}

Berdasarkan hasil penilaian media oleh ahli media didapat skor rata rata 87,08 (kategori baik) sedangkan oleh guru matematika sebagai ahli materi diperoleh skor ratarata 88,57 (kategori sangat baik) sehingga media termasuk dalam kategori valid. Dari hasil angket kepraktisan media pembelajaran video animasi Powtoon diperoleh skor ratarata 84,96 ( kategori praktis), sehingga memenuhi aspek kepraktisan yang ditinjau dari efektif, interaktif, menarik, efisien, dan kreatif. Sedangkan berdasarkan nilai posttest yang lebih tinggi dari pretest yaitu nilai posttest 81,50 lebih tinggi dari nilai pretest 67,57 bahwa media pembelajaran efektif digunakan. Berdasarkan analisis tersebut dapat disimpulkan bahwa media video animasi menggunakan software Powtoon telah memenuhi kriteria valid, praktis dan efektif.

\section{Daftar Pustaka}

[1] A. Muhson, "Pengembangan Media Pembelajaran Berbasis Teknologi Informasi," J. Pendidik. Akunt. Indones., vol. 8, no. 2, 2010.

[2] M. H. M. Hasyim, "Penerapan Fungsi Guru Dalam Proses Pembelajaran," $J$. Pendidik. Dasar Islam, vol. 1, no. 2, 2014.

[3] R. Abdullah, "Pembelajaran Dalam Perspektif Kreativitas Guru Dalam Pemanfaatan Media Pembelajaran," Lantanida J., vol. 4, no. 1, 2017.

[4] A. Arsyad, Media Pembelajaran. Jakarta: Raja Grafindo Persada, 2011.

[5] Daryanto, Media Pembelajaran. Yogyakarta: Satu Nusa Studio, 2010.

[6] D. Maryani, "Pembuatan Media Pembelajaran Interaktif Bangun Ruang Matematika," Speed - Sentra Penelit. Eng. dan Edukasi, vol. 6, no. 2, 2013.

[7] S. Sukiyasa, K., \& Sukoco, "Pengaruh media animasi terhadap hasil belajar dan motivasi belajar siswa materi sistem kelistrikan otomotif," J. Pendidik. Vokasi, vol. 3, no. 1, 2013.

[8] B. A. Raffaello, Pengembangan Media Pembelajaran Video Animasi Powtoon Pada Mata Pelajaran Pelayanan Penjualan di SMK Ketintang Surabaya. Jurnal Pendidikan Tata Niaga (JPTN), vol. 6, no. 4, 2018.

[9] R.Y. Astika, B.S. Anggoro, dan S. Andriani, "Pengembangan video media pembelajaran matematika dengan bantuan powtoon", JP3M, vol. 2, no.2, 2019, 8596

[10] Yulia, D., \& Ervinalisa, N. "Pengaruh Media Pembelajaran Powtoon pada Mata Pelajaran Sejarah Indonesia dalam Menumbuhkan Motivasi Belajar Siswa Kelas X di SMA Negeri 17 Batam Tahun Pelajaran 2017/2018". Historia, vol. 2, no.1, 2017

[11] T. P. Awalia, I., Pamungkas, A. S., \& Alamsyah, "Pengembangan Media Pembelajaran Animasi Powtoon pada Mata Pelajaran Matematika di Kelas IV SD,” Kreano, J. Mat. Kreat., vol. 10, no. 1, 2019.

[12] Sugiyono, Metode Penelitian Kuantitatif, Kualitatif, dan Kombinasi (Mixed Methods). Bandung: Alfabeta, 2010.

[13] S. Arikunto, Dasar-dasar Evaluasi Pendidikan (edisi revisi).Jakarta: Bumi Aksara 2009 